\title{
Influence of Hormonal Changes on Audiologic Examination in Normal Ovarian Cycle Females: An Analytic Study
}

\author{
Indri Adriztina ${ }^{1} \quad$ Adlin Adnan $^{1} \quad$ Ichwanul Adenin ${ }^{2}$ \\ ${ }^{1}$ Department of Otorhinolaryngology, Universitas Sumatera Utara, \\ Medan, North Sumatera, Indonesia \\ 2 Department of Obstetrics and Gynecology, Universitas Sumatera \\ Utara, Medan, North Sumatera, Indonesia \\ ${ }^{3}$ Department of Epidemiology training research advocacy and \\ teaching, Universitas Sumatera Utara, Medan, North Sumatra, \\ Indonesia
}

\author{
Siti Hajar Haryuna ${ }^{1}$ Sorimuda Sarumpaet ${ }^{3}$
}

Int Arch Otorhinolaryngol 2016;20:294-299.

\author{
Address for correspondence Indri Adriztina, MD, ENT specialist, \\ Department of Otorhinolaryngology, Universitas Sumatera Utara, jln \\ dr Mansyur no 9, Medan, Sumatera Utara 20155, Indonesia \\ (e-mail: adriztina@yahoo.com).
}

\begin{abstract}
Keywords

- menstrual cycle

- ovulation

- luteal phase

- follicular phase

- DPOAE

Introduction There is only limited information from previous studies that suggest that auditory function may be influenced by hormones. Recent advances in the field have exposed the potential role of hormones in modulating the auditory system.

Objective This study aims to investigate the relationship between menstrual cycle and outer hair cell function with audiological examination.

Methods This is an analytic study with a cross-sectional design. The sampling was a systematic random sampling. We found 49 women with normal menstrual cycle and collected their data through interviews, physical examination, and examination of the ear, with otoscopic and other routine otorhinolaryngology examinations. We evaluated Tympanometry, distortion-product otoacoustic emissions (DPOAE), and pure tone audiometry.

Results We found the audiometric threshold worse in the follicular phase than other phases at $4000 \mathrm{~Hz}$ of the right ear, and in the ovulation was found best than any other phases at $1000 \mathrm{~Hz}$ of the left ear with significant difference. We found significant difference of DPOAE between ovulation time and follicular phase at $3000 \mathrm{~Hz}$ and $1000 \mathrm{~Hz}$ in the left ear and between ovulation and luteal phased at $2000 \mathrm{~Hz}, 3000 \mathrm{~Hz}$ and $5000 \mathrm{~Hz}$ in the right ear and at $1000 \mathrm{~Hz}$ in the left ear with $p<0.05$.

Conclusion The result of this study showed that only a small part of audiometry threshold had a significant difference between each menstrual phase. In other words, we found no correlation between menstrual and audiometry threshold. Nonetheless, there is a correlation between menstrual cycle phase and DPOAE amplitude.
\end{abstract}

\section{Introduction}

Some researchers have proposed that women with hormonal changes may experience alterations in auditory functions, such as in menopause woman, woman with hormonal contraceptive, or even during the ovarian cycle. Previous studies suggest that even the physiological fluctuation in reproductive hormones - estrogen and progesterone - during the ovarian cycle may influence auditory function. ${ }^{1-3}$ Homeostasis and the biochemical status of inner ear fluid are essential for balance and for hearing. Changes in sodium and water reabsorption that take place during the ovarian cycle may received

August 19, 2015

accepted

September 28, 2015

published online

October 29, 2015
DOI http://dx.doi.org/

10.1055/s-0035-1566305. ISSN 1809-9777.
Copyright $(2016$ by Thieme Publicações License terms Ltda, Rio de Janeiro, Brazil
(ब) (1) $\circledast$ 
affect the functioning of this part of the peripheral auditory system, which could in turn affect homeostasis, causing auditory and labyrinthic symptoms. ${ }^{4}$

The ovarian cycle is divided into three phases:

- The follicular phase begins with menstrual bleeding and lasts, on average, 15 days. It is more variable in length than the other phases. Hormone levels are at their lowest point during this phase, especially during the first five days. Then, estrogen levels begin to rise until about day 13 to 14 , when ovulation occurs.

- The ovulatory phase lasts about three days, culminating in ovulation, with the release of an ovule. Estrogen reaches its peak level just before ovulation. Several studies found the estrogen receptor $\alpha(E R \alpha)$ and $\beta$ estrogen $\beta$ (ER $\beta)$ in the adult human cochlea (ER $\alpha$ in the spiral ganglion, and ER $\beta$ in the stria vascularis) and animal models with immunohistochemistry.

- The luteal phase lasts $\sim 14$ days and ends with the beginning of menstruation, when a new cycle begins. It does not vary much from month to month. In this phase, blood supply to the endometrium continues to increase due to the rising level of progesterone produced by the corpus luteum of the ovary, reaching its highest level around day 7, after ovulation. Progesterone levels peak in the luteal phase as LH/FSH levels decrease even further. High progesterone may increase sodium, chloride, and water reabsorption. Changes in sodium and water reabsorption that take place during the ovarian cycle may affect the function of this part of peripheral auditory system. Most of the changes in women take place in the luteal phase; these changes include fluid retention, weight gain, increased energy demands, changes in glucose uptake, a slower gastrointestinal transit time, and hydrops of the labyrinth (due to sodium retention and the resulting endolymph hypertension). ${ }^{4-10}$

Previous studies have reported on changes in auditory function during the ovarian cycle, focusing on various aspects such as auditory threshold and otoacoustic emission. Nonetheless, there has not been a reliable solution. The aim of this research is to investigate the influence of hormonal variation during the ovarian cycle on auditory threshold and outer hair cell function through the audiometry and distortion product otoacoustic emission (DPOAE) test and the correlation between both examinations, based on a relatively larger sample size. ${ }^{3,4,11-15}$

\section{Material and Methods}

\section{Subjects}

This is an analytic study with a cross-sectional design. We recruited forty-nine patients of reproductive age (20 to 40 years old) by systematic random sampling from the entire population of residents at Adam Malik General Hospital in North Sumatera, Indonesia, with an interval of 10 . The Health Research Ethical Committee granted approval for the study. All women reported a regular menstrual cycle ranging between 24 and 35 days. We documented positive LH surge using a commercial ovulatory kit in all women three months prior to the research, indicating they all had a normal ovulatory cycle. None of the women had been taking hormonal contraceptive or other drug treatment that could alter their auditory function (such as Cisplatin, aminoglycoside, hemodialysis). They had no history of endocrine pathology, hypertension, or otological conditions. All women had normal otoscopy, normal hearing and middle ear function, assessed by pure tone audiometry and tympanometry.

\section{Clinical Protocol}

The subjects underwent tests three times during one ovarian cycle, as follows:

- Follicular phase: Third day after menstruation, indicating the estrogen and progesterone are in the lowest level.

- Ovulation phase: After the ovulation times tested with the ovulatory kit, indicating the estrogen at a high level.

- Luteal phase: Seventh day after the ovulation, indicating the progesterone at a high level.

During each test session, the subjects underwent auditory tests including audiometry, tympanometry, and DPOAE. All auditory tests were held at the same time of the day for each subject, to control for the influence of physiological circadian variation.

\section{Material}

The same audiologist performed each test. For pure tone audiometry, to assess the hearing threshold, the audiologist used Audio Traveler AA222 (Interacoustics, Denmark). The tone pulses were 1-2 seconds in duration to avoid adaptation with ascending sound technique, according to the recommendation from the American Speech-language Hearing Association. ${ }^{16}$ The tests were at the frequencies of $250 \mathrm{~Hz}$, $500 \mathrm{~Hz}, 1000 \mathrm{~Hz}, 2000 \mathrm{~Hz}, 4000 \mathrm{~Hz}$, and $8000 \mathrm{~Hz}$. We excluded patients with conductive hearing loss.

The patients underwent tympanometry to determine the function of middle ear. Using $226-\mathrm{Hz}$ probe tone, the middle ear pressure had to be between $-100 \mathrm{~Pa}$ and $+50 \mathrm{~Pa}$. The peak value of compliance was in the range between 0.3 and 1.6 $\mathrm{cm}^{3}$. This indicated good tympanic membrane mobility and normal middle ear pressure, enabling a valid otoacoustic emission recording. For the test, we used the Audio Traveler AA222 tympanometer (Interacoustics, Denmark).

As for the DPOAE, to assess outer hair cell of the cochlea function, the examiner recorded DPOAE via an ear canal probe inserted into the ear canal. The examination was done at the frequencies of $1000 \mathrm{~Hz}, 2000 \mathrm{~Hz}, 3000 \mathrm{~Hz}$, $4000 \mathrm{~Hz}$, and $5000 \mathrm{~Hz}$. Signal-to-noise ratio had to be $3 \mathrm{~dB}$ or higher at each frequency. The device used in this test was the Elios (Echodia, France).

\section{Statistical Analysis}

We analyzed all of the data with SPSS (Statistical Package for the Social Science), adopting a 0.05 significance level for statistical purposes. Using the paired sample $t$-test, we observed the effect of the menstrual cycle phase on OAE and audiometry. 


\section{Result}

The sample consisted of 49 women of reproductive age. Patientś ages ranged from 24 to 36 years, with a mean of 27.35 years. We found a bigger sample size in the age group of $20-30$ years old ( $85.7 \%$ ) than in the age group of $31-40$ years (14.3\%).

\section{Pure Tone Audiometry}

The difference between pure tone audiometry threshold of follicular and ovulation phase was found significant at $1000 \mathrm{~Hz}$ on the left ear $(p=0.005)$ and at $4000 \mathrm{~Hz}$ on the right ear $(p=0.008)$, as shown in - Table 1 . We also found a significant difference between pure tone audiometry threshold of ovulation and luteal phase at $1000 \mathrm{~Hz}(p=0.003)$ on the left ear, as shown in - Table 2, and between follicular and luteal phase at $4000 \mathrm{~Hz}(p=0.013)$ on the right ear, as shown in -Table 3.

Based on this result, we found that right ear pure-tone audiometry at the frequency of $4000 \mathrm{~Hz}$ in the follicular phase presents the worst hearing threshold $(9.08 \mathrm{~dB})$, in comparison with the ovulation period $(7.35 \mathrm{~dB})$ and luteal phase $(7.00$ $\mathrm{dB})$. Although the hearing threshold was in the normal range, we found significant differences $(p<0.05)$ between follicular phases and between other phases at the frequency of $4000 \mathrm{~Hz}$, showing a slight fluctuation of the hearing function. Furthermore, left ear pure-tone audiometry at the frequency of $1000 \mathrm{~Hz}$ produced the best results $(16.33 \mathrm{~dB})$, in comparison with the follicular phase $(18.67 \mathrm{~dB})$, and luteal phase $(18.57 \mathrm{~dB})$, with significant differences $(p<0.005)$.

\section{DPOAE}

A significant difference was found between DPOAE amplitudes of the follicular phase and ovulation, at $1000 \mathrm{~Hz}$ $(p=0.022)$ and $3000 \mathrm{~Hz}(p=0.000)$ on the left ear, as shown in - Table 4. Between the DPOAE amplitudes of ovulation and luteal phase, there were several significantly different frequencies found, including $2000 \mathrm{~Hz}, 3000 \mathrm{~Hz}$, and $5000 \mathrm{~Hz}$ in the right ear $(p<0.05)$ and $1000 \mathrm{~Hz}, 2000 \mathrm{~Hz}$, and $3000 \mathrm{~Hz}$ at the left ear $(p<0.05)$, as shown in - Table 5 . We found no significant differences between DPOAE amplitudes of follicular phase and luteal phase, as shown in - Table 6 .

\section{Discussion}

Several hormones have been known to modulate auditory function. Many studies have found that several different hormone receptors are located in the mammalian cochlea. This condition may cause alteration of auditory function in patient who suffer hormone deficiency, hormone hypersecretion or patient that have hormonal replacement therapy. ${ }^{17-20}$ Interestingly, alteration in auditory function also occurs during physiological changes such as the ovarian cycle. Previous data found different hearing sensitivity levels in

Table 1 Pure-tone audiometry analysis results, considering mean hearing threshold at each frequency and comparison between the follicular phase and ovulation for each ear

\begin{tabular}{|c|c|c|c|c|c|c|}
\hline \multirow[t]{2}{*}{ Frequency } & \multicolumn{2}{|l|}{ Right ear (dB) } & \multirow[b]{2}{*}{ p-value } & \multicolumn{2}{|l|}{ Left ear (dB) } & \multirow[b]{2}{*}{ p-value } \\
\hline & Follicular Phase & Ovulation & & Follicular Phase & Ovulation & \\
\hline $250 \mathrm{~Hz}$ & 19.90 & 19.08 & 0.315 & 19.59 & 19.39 & 0.808 \\
\hline $500 \mathrm{~Hz}$ & 19.90 & 19.29 & 0.518 & 19.29 & 18.57 & 0.376 \\
\hline $1000 \mathrm{~Hz}$ & 18.00 & 18.39 & 0.593 & 18.67 & 16.33 & 0.005 \\
\hline $2000 \mathrm{~Hz}$ & 11.12 & 11.22 & 0.898 & 11.63 & 10.00 & 0.051 \\
\hline $4000 \mathrm{~Hz}$ & 9.08 & 7.35 & 0.008 & 7.55 & 7.45 & 0.908 \\
\hline $8000 \mathrm{~Hz}$ & 4.59 & 4.29 & 0.764 & 6.22 & 4.59 & 0.125 \\
\hline
\end{tabular}

Table 2 Pure-tone audiometry analysis results, considering mean hearing threshold at each frequency and comparison between ovulation and luteal phase for each ear

\begin{tabular}{|l|l|l|l|l|l|l|}
\hline \multirow{2}{*}{ Frequency } & \multicolumn{2}{l|}{ Right ear $(\mathrm{dB})$} & & \multicolumn{2}{l|}{ Left ear $(\mathrm{dB})$} & \\
\cline { 2 - 8 } & Ovulation & Luteal Phase & $p$-value & Ovulation & Luteal Phase & -value \\
\hline $\mathbf{2 5 0 ~ H z}$ & 19.08 & 18.47 & 0.508 & 19.39 & 18.00 & 0.521 \\
\hline $\mathbf{5 0 0 ~ H z}$ & 19.29 & 19.49 & 0.808 & 18.57 & 18.88 & 0.700 \\
\hline $\mathbf{1 0 0 0 ~ H z}$ & 18.39 & 17.14 & 0.114 & 16.33 & 18.57 & 0.003 \\
\hline $\mathbf{2 0 0 0 ~ H z}$ & 11.22 & 10.10 & 0.140 & 10.00 & 10.51 & 0.390 \\
\hline $\mathbf{4 0 0 0 ~ H z}$ & 7.35 & 7.00 & 0.625 & 7.45 & 7.14 & 0.679 \\
\hline $\mathbf{8 0 0 0 ~ H z}$ & 4.29 & 5.82 & 0.104 & 4.59 & 5.71 & \\
\hline
\end{tabular}


Influence of Hormonal Changes in Normal Ovarian Cycle Females Adriztina et al. 297

Table 3 Pure-tone audiometry analysis results, considering mean hearing threshold at each frequency and comparison between follicular and luteal phases for each ear

\begin{tabular}{|l|l|l|l|l|l|l|}
\hline \multirow{2}{*}{ Frequency } & \multicolumn{2}{|l|}{ Right ear $(\mathrm{dB})$} & & \multicolumn{2}{l|}{ Left ear (dB) } & \multicolumn{1}{l|}{} \\
\cline { 2 - 7 } & Follicular Phase & Luteal Phase & $p$-value & Follicular Phase & Luteal Phase & $p$-value \\
\hline $250 \mathrm{~Hz}$ & 19.90 & 18.47 & 0.142 & 19.59 & 18.00 & 0.442 \\
\hline $500 \mathrm{~Hz}$ & 19.90 & 19.49 & 0.667 & 19.29 & 18.88 & 0.633 \\
\hline $1000 \mathrm{~Hz}$ & 18.00 & 17.14 & 0.052 & 18.67 & 18.57 & 0.904 \\
\hline $2000 \mathrm{~Hz}$ & 11.12 & 10.10 & 0.207 & 11.63 & 10.51 & 0.154 \\
\hline $\mathbf{4 0 0 0 ~ H z}$ & 9.08 & 7.00 & 0.013 & 7.55 & 6.14 & 0.622 \\
\hline $\mathbf{8 0 0 0 ~ H z}$ & 4.59 & 5.82 & 0.248 & 6.22 & 5.71 & 0.694 \\
\hline
\end{tabular}

Table 4 DPOAE analysis, considering mean amplitudes at each frequency and comparison between follicular phase and ovulation for each ear

\begin{tabular}{|c|c|c|c|c|c|c|}
\hline \multirow[t]{2}{*}{ Frequency } & \multicolumn{2}{|l|}{ Right ear (dB) } & \multirow[b]{2}{*}{ p-value } & \multicolumn{2}{|l|}{ Left ear (dB) } & \multirow[b]{2}{*}{ p-value } \\
\hline & Follicular Phase & Ovulation & & Follicular Phase & Ovulation & \\
\hline $1000 \mathrm{~Hz}$ & 4.55 & 5.35 & 0.181 & 5.02 & 6.61 & 0.022 \\
\hline $2000 \mathrm{~Hz}$ & 7.27 & 7.96 & 0.170 & 6.33 & 7.51 & 0.060 \\
\hline $3000 \mathrm{~Hz}$ & 2.78 & 4.22 & 0.070 & 2.22 & 5.67 & 0.000 \\
\hline $4000 \mathrm{~Hz}$ & 4.59 & 4.20 & 0.690 & 5.08 & 6.57 & 0.263 \\
\hline $5000 \mathrm{~Hz}$ & 5.14 & 7.14 & 0.063 & 5.82 & 7.02 & 0.218 \\
\hline
\end{tabular}

Table 5 DPOAE analysis, considering mean amplitudes at each frequency and comparison between ovulation and luteal phase for each ear

\begin{tabular}{|l|l|l|l|l|l|l|}
\hline \multirow{2}{*}{ Frequency } & \multicolumn{2}{l|}{ Right ear $(\mathrm{dB})$} & & \multicolumn{2}{l|}{ Right ear (dB) } & \\
\cline { 2 - 7 } & Ovulation & Luteal Phase & $p$-value & Ovulation & Luteal Phase & $p$-value \\
\hline $1000 \mathrm{~Hz}$ & 5.35 & 4.55 & 0.295 & 6.61 & 5.18 & 0.013 \\
\hline $2000 \mathrm{~Hz}$ & 7.96 & 6.29 & 0.003 & 7.51 & 5.69 & 0.005 \\
\hline $3000 \mathrm{~Hz}$ & 4.22 & 2.16 & 0.003 & 5.67 & 3.71 & 0.014 \\
\hline $4000 \mathrm{~Hz}$ & 4.20 & 3.47 & 0.417 & 6.57 & 4.67 & 0.064 \\
\hline $5000 \mathrm{~Hz}$ & 7.14 & 5.29 & 0.034 & 7.02 & 5.53 & 0.113 \\
\hline
\end{tabular}

Table 6 DPOAE analysis, considering mean amplitudes at each frequency and comparison between follicular phase and luteal phase for each ear

\begin{tabular}{|l|l|l|l|l|l|l|}
\hline \multirow{2}{*}{ Frequency } & \multicolumn{2}{|l|}{ Right ear (dB) } & & \multicolumn{2}{l|}{ Left ear (dB) } & \multicolumn{2}{l|}{} \\
\cline { 2 - 8 } & Follicular Phase & Luteal Phase & $p$-value & Follicular Phase & Luteal Phase & $p$-value \\
\hline $1000 \mathrm{~Hz}$ & 4.55 & 4.55 & 1.000 & 5.02 & 5.18 & 0.782 \\
\hline $2000 \mathrm{~Hz}$ & 7.27 & 6.29 & 0.167 & 6.33 & 5.69 & 0.260 \\
\hline $3000 \mathrm{~Hz}$ & 2.78 & 2.16 & 0.445 & 2.22 & 3.71 & 0.112 \\
\hline $4000 \mathrm{~Hz}$ & 4.59 & 3.47 & 0.249 & 5.08 & 4.67 & 0.713 \\
\hline $5000 \mathrm{~Hz}$ & 5.14 & 5.29 & 0.872 & 5.82 & 5.53 & 0.726 \\
\hline
\end{tabular}


each phase of the ovarian cycle with various parameters, from peripheral to the central auditory system..$^{3,14,21-24}$ It also has been reported that sensorineural deafness in high frequency can occur with the onset of menstruation. ${ }^{15}$

We found that hearing threshold at the frequency of $4000 \mathrm{~Hz}$ of the right ear in the follicular phase was worse than in ovulation and luteal phase. Whereas, hearing threshold at ovulation at the frequency of $1000 \mathrm{~Hz}$ of the left ear was better than in the follicular and luteal phases. At follicular phase, we know that estrogen level is at the lowest point. The condition seemed to cause the alteration in auditory function. Previous studies showed a worsening of hearing threshold in the follicular phase or in the early days of menstruation.

Conversely, estrogen during ovulation is high, which may cause a better hearing threshold. Swanson and Dengerink found better hearing thresholds during ovulation at the frequency of $4000 \mathrm{~Hz} .{ }^{12,14}$ Previous studies have found estrogen receptors in the cochlea by immunohistochemistry. In a study on animals, if severe progressive hearing loss occurred in the inner ear ER $\beta$ knock-out mice. These receptors maintain fluid and electrolyte balance in cochlea. This condition could cause alteration in fluid and electrolyte balance, leading to a disturbance of estrogen level that results in auditory alteration. ${ }^{17,25-27}$ In this study, we found that only limited frequencies were disturbed by the hormone fluctuation in ovarian cycle. This shows that the ovarian cycle generally does not influence hearing function. In this research, we also conducted DPOAE examination to evaluate cochlear function. Otoacoustic emissions (OAE) are sounds that arise in the ear canal when the tympanum receives vibration transmitted backward through the middle ear from the cochlea. Distortion product otoacoustic emissions (DPOAE), detected using two stimulus tones from the ear canal, and non-linear intermodulation between the two stimuli, generate several new acoustic frequency components inside the healthy cochlea, which can travel to the ear canal. Therefore, DPOAE can detect abnormalities of the cochlear function. ${ }^{28}$

We found a significant difference between DPOAE amplitudes during ovulation time and the follicular phase at the frequencies of $1000 \mathrm{~Hz}$ and $3000 \mathrm{~Hz}$ in the left ear $(p<0.05)$. We also found significant differences between ovulation time and the luteal phase at the frequencies of $2000 \mathrm{~Hz}, 3000 \mathrm{~Hz}$, and $5000 \mathrm{~Hz}$ in the right ear, and $1000 \mathrm{~Hz}, 2000 \mathrm{~Hz}$, and $3000 \mathrm{~Hz}$ in the left ear. Our study was similar to Al-Mana's, which found a significant different between OAE amplitude of early follicular phase and the luteal phase, both early and late. $^{3}$

The result of DPOAE examination was the representation of well-integrated outer hair cells in the cochlea. There were higher DPOAE amplitudes during ovulation in comparison to any other phase. This may be a result of a higher estrogen level at ovulation time, which has a positive effect on auditory function. Estrogen, aside from maintaining the balance of fluid and electrolytes in the cochlea, facilitates auditory information by enhancing glutamatergic neurotransmission, playing a role in neuroprotection. In a recent study, Wang and colleagues reported that estrogen has a protective effect against noise exposure. Studies have found that estrogen relates to caspase- 3 intensity. Caspase- 3 are pro-apoptotic agents which become a precursor to the hair cell apoptotic process in the cochlea upon noise exposure. ${ }^{3,4,13,29}$

We found no significant difference of DPOAE amplitude in the luteal phase in comparison to the follicular phase. In the luteal phase, we know that progesterone is at a high level; whereas in the follicular phase, both estrogen and progesterone are low. This fact showed that physiological changes in progesterone did not affect auditory function. Previous research reports that progesterone replacement therapy has a detrimental effect on hearing function, as unnatural levels of progesterone could be detrimental to hearing in females. However, our findings show that the fluctuation of progesterone level in normal ranges has no effect on auditory function. ${ }^{18,30,31}$

\section{Conclusion}

Pure tone audiometry is an examination to evaluate hearing function in general, while DPOAE is a test for evaluating integration of outer hair cell of the cochlea. The result of this study showed that only a small part of audiometry threshold had a significant difference between each phase of ovarian cycle; whereas the DPOAE product shows statistically significant differences at several frequencies between the phases. In other words, we found no correlation between menstrual and auditory threshold. There is, however, a correlation between phases of ovarian cycle and outer hair cell function.

\section{References}

1 Hederstierna C, Hultcrantz M, Collins A, Rosenhall U. Hearing in women at menopause. Prevalence of hearing loss, audiometric configuration and relation to hormone replacement therapy. Acta Otolaryngol 2007;127(2):149-155 10.1080/00016480600794446

2 Mitre EI, Figueira AS, Rocha AB, Alves SMC. Audiometric and vestibular evaluation in women using the hormonal contraceptive method. Braz J Otorhinolaryngol 2006;72(3):350-354

3 Al-Mana D, Ceranic B, Djahanbakhch O, Luxon LM. Alteration in auditory function during the ovarian cycle. Hear Res 2010;268; (1-2):114-122

4 Arruda PO, Silva IMC. Study of otoacoustic emissions during the female hormonal cycle. Braz J Otorhinolaryngol 2008;74(1):106-111

5 Ishii C, Nishino LK, Campos CAH. Vestibular characterization in the menstrual cycle. Braz J Otorhinolaryngol 2009;75(3):375-380

6 Mtawalli G, Pina M. Angle, Murphy C. The menstrual cycle and its relation to contraceptive methods: a reference for reproductive health trainers. INTRAH. University of North Caroline; 1997:14

7 Farage MA, Neill S, MacLean AB. Physiological changes associated with the menstrual cycle: a review. Obstet Gynecol Surv 2009; 64(1):58-72 10.1097/OGX.0b013e3181932a37

8 Poromaa IS, Gingnell M. Menstrual cycle influence on cognitive function and emotion processing - from a reproductive perspective. Front Neurosci 2014;8:1-16 10.3389/fnins.2014.00380

9 Stenberg AE, Wang H, Fish J III, Schrott-Fischer A, Sahlin L, Hultcrantz M. Estrogen receptors in the normal adult and developing human inner ear and in Turner's syndrome. Hear Res 2001; 157(1-2):87-92

10 Charitidi K, Meltser I, Canlon B. Estradiol treatment and hormonal fluctuations during the estrous cycle modulate the expression of 
estrogen receptors in the auditory system and the prepulse inhibition of acoustic startle response. Endocrinology 2012; 153(9):4412-4421

11 Yellin MW, Stillman RD. Otoacoustic emissions in normal-cycling females. J Am Acad Audiol 1999;10(7):400-408

12 Cox JR. Hormonal influence on auditory function. Ear Hear 1980; 1(4):219-222

13 Gurbuzler L, Yelken K, Aladag I, Eyibilen A, Koc S. Comparison of transient and distortion-product otoacoustic emissions during the luteal and follicular phases of the menstrual cycle. Ear Nose Throat J 2012;91(8):322-334

14 Swanson SJ, Dengerink HA. Changes in puretone threshold and temporary shifts as a function of menstrual cycle and oral contraceptive. J Speech Hear Res 1988;31(4):569-574

15 Souaid JP, Rappaport JM. Fluctuating sensorineural hearing loss associated with the menstrual cycle. J Otolaryngol 2001;30(4): 246-250

16 American Speech-Language Hearig Association. Guidelines for Manual Pure-Tone Threshold Audiometry [Guidelines]. 2005. Available at: www.asha.org/policy. Accesed 15 Jan 2012

17 Al-Mana D, Ceranic B, Djahanbakhch O, Luxon LM. Hormones and the auditory system: a review of physiology and pathophysiology. Neuroscience 2008;153(4):881-900

18 Price K, Zhu X, Guimaraes PF, Vasilyeva ON, Frisina RD. Hormone replacement therapy diminishes hearing in peri-menopausal mice. Hear Res 2009;252(1-2):29-36

19 Malik V, Shukla GK, Bhatia N. Hearing profile in hypothyroidism. Ind J Otolaryngol Head Neck Surg 2002;54(4):285-290

20 Kucur C, Kucur SK, Gozukara I, et al. Extended high frequency audiometry in polycystic ovary syndrome. Scientific World Journal 2013;2013:482689
21 Walpurger V, Pietrowsky R, Kirschbaum C, Wolf OT. Effects of the menstrual cycle on auditory event-related potentials. Horm Behav 2004;46(5):600-606

22 Serra A, Maiolino L, Agnello C, Messina A, Caruso S. Auditory brain stem response throughout the menstrual cycle. Ann Otol Rhinol Laryngol 2003;112(6):549-553

23 Yadav A, Tandon OP, Vaney N. Auditory evoked responses during different phases of menstrual cycle. Indian J Physiol Pharmacol 2002;46(4):449-456

24 Mann N, Sidhu RS, Babbar R. Brainstem auditory evoked responses in different phases of menstrual cycle. J Clin Diagn Res 2012;6(10): 1640-1643

25 Simonoska RSex steroid hormone receptors: Inner Ear Hearing, Karolinska Insitute, Stockholm, 2009:31

26 Hultcrantz M, Simonoska R, Stenberg AE. Estrogen and hearing: a summary of recent investigations. Acta Otolaryngol 2006;126(1): $10-14$

27 Nolan LS, Maier H, Hermans-Borgmeyer I, et al. Estrogen-related receptor gamma and hearing function: evidence of a role in humans and mice. Neurobiol Aging 2013;2077:1-9

28 Kemp DT. Otoacoustic emissions, their origin in cochlear function, and use. Br Med Bull 2002;63:223-241

29 Wang H, Wu W, Han H, Li B, Wang G, Yu M. Estrogen reduces caspase-3 expression in the inner ear of guinea pigs exposed to stimulated microgravity and inboard noises of spaceship. Int Adv Otol 2014;10(10):25-29 10.5152/lao.2014.005

30 Frisina RD. Hormones and hearing: too much or too little of good thing can be ototoxic. Semin Hear 2012;33(3):231-241

31 Guimaraes P, Frisina ST, Mapes F, Tadros SF, Frisina DR, Frisina RD. Progestin negatively affects hearing in aged women. Proc Natl Acad Sci U S A 2006;103(38):14246-14249 